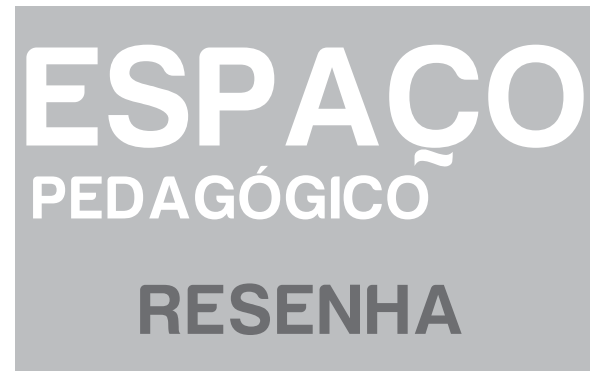





\section{Aprendizagem e formação humana ${ }^{1}$}

\section{Nara A. Peruzzo*}

Em seu livro Para além da aprendizagem: educação democrática para um futuro humano, recentemente publicado pela Editora Autêntica, o professor de Teoria da Educação e Política da Universidade de Luxemburgo, Gert Biesta, discute sobre o papel da educação em uma sociedade democrática. Critica a compreensão humanista de educação e propõe uma nova forma de abordar a educação.

Para o autor, há limites na compreensão moderna de educação, uma vez que parte da compreensão de uma natureza humana racional, ou seja, preocupa-se $a$ priori em dizer quem é o ser humano, tornando-se, nesse sentido, o papel da educação "revelar ou liberar" (p. 18) o potencial de sujeito automotivado e autodirigido. Partindo dessa crítica, justifica seu pensamento sobre uma nova abordagem de educação que não centra na concepção a priori do ser humano e, por isso, usa o termo "a educação pós a morte do sujeito". Com tal abordagem, pretende considerar o ser humano "como uma questão radicalmente aberta" (p. 19).

Para cumprir com seu objetivo, estrutura o texto em seis capítulos, articulando-os entre si a partir do problema exposto. No primeiro capítulo, intitulado "Contra a aprendizagem: recuperando uma linguagem para a educação numa era da aprendizagem", tematiza o que constitui uma relação educacional e a importância de recuperar uma linguagem à educação, e não somente à aprendizagem. Com isso, critica a educação tecnicista e, por consequência, o próprio modelo neoliberal que a sustenta.

Considera a linguagem um elemento importante para a educação, pois influencia tanto o que pode ser dito como o que não pode ser dito. É nesse sentido que, para o autor, ocorreu, nas últimas décadas, uma transformação na linguagem dos educadores: a linguagem da educação foi substituída pela linguagem da aprendizagem. Muito mais do que um jogo linguístico, essa substituição tem sérias consequências para o campo educacional. A educação passou a ser compreendida como tarefa de apoiar ou facilitar a aprendizagem, a qual denota a apreensão de conteúdos e técnicas. Essa nova linguagem é decorrente de quatro tendências, a sa-

Recebido: 25/08/2013 - Aprovado: 10/10/2013

http://dx.doi.org/10.5335/rep.v21i1.3881

Doutoranda no Programa de Pós-Graduação em Educação, da Universidade de Passo Fundo/RS. E-mail: naracyda@hotmail.com 
ber: a) novas teorias da aprendizagem; b) pós-modernismo; c) a explosão silenciosa da aprendizagem adulta (centrada muito mais no individualismo, tanto na forma como no conteúdo e objetivo); e d) a erosão do Estado de bem-estar social.

$\mathrm{O}$ grande problema da nova linguagem da aprendizagem, segundo o autor, é que "ela tem facilitado uma nova descrição do processo da educação em termos de uma transação econômica" (p. 37). Isto é, o aprendente é o consumidor; o professor ou a instituição educacional, o provedor; e, com isso, a educação é transformada em mercadoria. Essa relação, embora silenciosa, está presente nas instituições educacionais, exigindo que a linguagem volte-se à aprendizagem, ou seja, à técnica e ao mercado de trabalho. Nesse modelo educacional, o aluno/consumidor, supostamente, sabe o que deseja da Instituição de Ensino/provedor, e esta, pelo pagamento do seu consumidor, deve satisfazer suas necessidades. Isso é problemático, para o autor, porque se compreende mal tanto o papel do educando quanto o do educador. Enquanto isso, a educação poderia ser o próprio processo de descoberta do que se deseja e os professores, aqueles que desempenham papel importante nessa descoberta.

Outro problema, presente nessa nova linguagem da aprendizagem, é a predefinição das necessidades do aprendente, considerando como nuclear apenas questões técnicas e não permitindo a proposição de questões sobre o conteúdo e o objetivo da educação. Ou seja, a linguagem da aprendizagem reduz a questão educacional mais ampla ao manuseio didático instrumental: o "como" ganha preferência em relação ao "o quê" e ao "para quê" educacional.

No cenário brasileiro, essa crítica faz-se muito presente, principalmente nas novas modalidades de ensino, nos cursos oferecidos, nas praticidades de ensino, nos currículos e no lugar de ensino. No texto, o autor cita o exemplo da learndirect, existente no Reino Unido. De nossa parte, podemos relacionar esse modo de ensino, no Brasil, com algumas modalidades de ensino a distância.

Diante desse cenário, Biesta entende que há a necessidade de "reivindicar - ou, antes, reinventar - uma nova linguagem da educação" (p. 43). Mas em que consistiria essa nova linguagem? Ou, melhor, o que constitui uma relação educacional nessa nova linguagem? Segundo o autor, a resposta a essa pergunta dar-se-á em torno de três conceitos entrelaçados: confiança, violência e responsabilidade. Ao discorrer sobre esses três pontos, Biesta tenta mostrar como é possível pensar uma relação educacional que não esteja baseada numa verdade particular de ser humano (humanismo), e muito menos num processo de produção "de um tipo particular de subjetividade" (p. 53) (sujeito racional moderno), mas que considere os indivíduos como seres únicos e singulares, que possam vir ao mundo. É nesse ponto que reside o aspecto central da argumentação do autor. Para o autor, "uma 
das principais responsabilidades educacionais é a de propiciar oportunidades para que os indivíduos venham ao mundo". Ele esclarece, na mesma passagem, tal significado: "Vir ao mundo não consiste definitivamente em autoexpressão. Consiste em entrar no tecido social e ser, portanto, inteiramente relacional. Consiste em responder ao outro e assim ser também responsável pelo que é o outro e por quem é o outro" (p. 48).

O segundo capítulo intitula-se "Tornar-se presença: a educação depois da morte do sujeito". O problema central que o perpassa é como superar a compreensão humanista de ser humano presente na educação, transformando a questão “quem é o sujeito?" na questão “onde o sujeito torna-se presença?". Para o autor, tornamo-nos presença por meio das relações com os outros que não são como nós. Assim, afirma ele: "O que nos torna únicos nessas relações, o que nos constitui como seres singulares e únicos, deve ser encontrado na dimensão ética dessas relações" (p. 56). O espaço onde o sujeito torna-se presença é intersubjetivo, pois ninguém se torna presença sozinho. É por isso que a pergunta que nos torna seres singulares não é “Onde estou?", mas Onde está você? (p. 80). E essa última é que interessa à educação.

No terceiro capítulo, "A comunidade daqueles que não têm nada em comum: educação e a linguagem da responsabilidade”, o problema central pode ser traduzido, como o próprio autor apresenta no prólogo, na tentativa de compreender a comunidade em que os indivíduos podem tornar-se presença. Ou, em outras palavras, o que significa vir ao mundo povoado por outros que não são como nós? A tese central do capítulo repousa na ideia da subjetividade enquanto natureza ética. Isso quer dizer que nos constituímos enquanto seres únicos e singulares pela maneira como respondemos à outridade do outro. Ora, é a comunidade que nos proporciona isso.

No quarto capítulo, "Quão difícil deve ser a educação?", o autor analisa as questões de fundo do campo educacional. A pergunta enunciada no título do capítulo é decorrente da seguinte tese do autor: "só podemos vir ao mundo se outros também podem vir ao mundo, o que significa que nossa vinda ao mundo depende da existência da pluralidade e da diferença" (p. 26). É por conta dessa exigência capital que a educação torna-se difícil, pois cabe a ela manter a existência de um espaço que proporcione que os sujeitos possam vir ao mundo. A questão estaria resolvida de antemão se não nos importássemos com a vinda de outros ao mundo, significando isso o mais puro individualismo; o ser humano paga um preço alto para viver assim.

No quinto capítulo, "A arquitetura da educação: criando um espaço mundano", o autor dá prosseguimento à reflexão anterior: se é papel da educação manter espaços que proporcionem a vinda ao mundo de sujeitos singulares e únicos, como 
deverão constituir-se esses espaços? Para responder a essa pergunta, recorre a alguns exemplos de arquiteturas, refletindo sobre a possibilidade de criar um espaço sem pré-defini-lo, ou seja, sem determiná-lo a priori. A análise resulta em um paradoxo: mesmo que a arquitetura não queira pré-determiná-lo, a funcionalidade dos espaços acaba por fazê-lo. O mesmo ocorre na educação. Ele conclui afirmando que "a responsabilidade [dos educadores] acarreta um dever duplo: para a educação e para seu desfazer" (p. 28).

O último capítulo, intitulado "A educação e a pessoa democrática”, é, ao nosso entendimento, o capítulo central de toda a argumentação do autor. Por ser o último capítulo, pressupõe-se que o autor percorreu um caminho até alcançar o fim desejável, ou seja, a justificação da educação democrática, ou, melhor, o papel da educação numa sociedade democrática. O problema central do capítulo é formulado pelo autor nas duas seguintes perguntas: "Mas como devemos compreender a relação entre democracia e educação? E qual é o papel das escolas numa sociedade democrática?" (p. 157). Essas perguntas são centrais não só à abordagem do autor como também ao debate atual da educação. Nesse contexto, ele recupera, com aprofundamento teórico, e problematiza a compreensão do que significa a "produção" da pessoa democrática.

Sua problematização acerca dessa questão orienta-se em três aspectos: a) a concepção tecnicista que concebe a educação como instrumento para produzir democracia; b) a abordagem individualista que visa a dar aos indivíduos conhecimento e habilidades sem questionar as relações sociais e o contexto social político em que aprendem e agem; c) a ideia de que a democracia só é possível se todos os cidadãos são adequadamente educados e agem de acordo com essa condição (p. 158-159).

A partir desses três problemas, levantados em torno da ideia de "produção", o autor questionará sobre a possibilidade de superar essa visão, considerando que a democracia consiste em pluralidade e diferença, e não na identidade e na uniformidade. Para refletir sobre esse tema, remontará a três outras concepções de pessoa democrática: concepção individualista (Kant), social (Dewey) e política (Arendt). É inspirado no pensamento de Arendt que Biesta, enfim, apresenta, no seu entendimento, os limites das concepções individualista e social. E é na compreensão política de subjetividade democrática de Arendt que encontra resposta às suas perguntas iniciais. Afirma, nesse contexto, de modo lapidar, o seguinte: "Para Arendt, a subjetividade não é definida pelos atributos de um indivíduo, mas compreendida como uma qualidade da interação humana" (p. 180).

Segundo o autor, Arendt localiza a subjetividade na esfera da interação humana, e não no "interior" do indivíduo, e justamente por isso ela nos permite 
pensar diferente a relação entre educação e democracia. A relação que se estabelece não é aquela de produzir sujeitos democráticos, mas a de criar condições para que os estudantes sejam sujeitos, que experimentem o que é e significa ser um sujeito. Mais uma vez, nas palavras de Biesta: "A aprendizagem relacionada a essa experiência não é algo que vem antes da subjetividade democrática. [...] a aprendizagem que está em jogo é a aprendizagem que resulta de ter sido ou não ter sido um sujeito" (p. 189).

Por fim, seguindo esse raciocínio, o autor chega à sua tese nuclear: a responsabilidade da educação democrática é da sociedade em geral, e não somente das escolas. Segundo ele, em uma sociedade em que os sujeitos não são capazes de agir (Arendt), ou não têm permissão para agir, não se pode esperar que as escolas produzam cidadãos democráticos (p. 189). Então, qual o papel da escola? Para Biesta, é a de sustentar sociedades em que a ação e a subjetividade são possibilidades reais.

Trata-se, sem dúvida, de um livro instigante, cujo conteúdo nos leva a refletir sobre muitos problemas da "questão educacional" atual. Contudo, a ausência de um diálogo mais pontual com a educação moderna impõe alguns limites à abordagem do autor, sobretudo, no que se refere à sua concepção de democracia. A título de exemplo, entendemos que uma compreensão de pessoa democrática, enunciada por Rousseau, poderia elucidar algumas questões do texto e minimizar os limites apresentados naquilo que Biesta chamou de "concepção individualista de educação democrática". Para Rousseau, o sujeito é um ser em aberto, ou seja, não é predeterminado, estabelecendo uma relação com o meio. Nesse sentido, ele concebe que foram as diversas transformações ocorridas no habitat natural que conduziram o ser humano à socialização. Ele é um ser em constante aperfeiçoamento.

O ser humano precisa aprender a ser democrático, ocorrendo esse aprender em duplo sentido: pela formação de conteúdos (tutor de Emílio) e pela experiência (viagens de Emílio). Ele precisa formar-se cidadão para ser cidadão, e isso quer dizer que ele não é cidadão por decreto, nem a priori, nem a posteriori. Ou seja, o educando forma-se ou não homem e cidadão pela sua própria experiência, com o auxílio de seu preceptor. Ele se constitui no processo de sua própria experiência, permanecendo em aberto a possibilidade de tornar-se o que ele é.

Nessa perspectiva, entendemos que não há uma anterioridade ou posterioridade entre escola e sociedade, como apresentado pelo autor, e que é de ambas a responsabilidade para a educação democrática. Afinal, do contrário, incorreríamos no equívoco de esperar uma sociedade que permita o agir, em vez de tencionarmos para o direito de agir.

Para concluir, ressaltamos a importância de Para além da aprendizagem: educação democrática para um futuro humano, pelas diversas questões e problemati- 
zações que consegue trazer à tona. É um referencial relevante para os educadores e todos aqueles que se interessam pelas questões educacionais. Ao ler o texto, somos levados a fazer diversos questionamentos sobre nossa prática educativa e sobre os rumos da educação contemporânea.

\section{Notas}

1 Resenha: BIESTA, Gert. Para além da aprendizagem: educação democrática para um futuro humano. Trad. de Rosaura Eichenberg. Belo Horizonte: Autêntica, 2013. 